\title{
Integrated System for Food and Agriculture Decision Makers
}

\author{
Pratap Narain \\ B 286 Yojana Vihar, Delhi - 110092, India
}

Copyright $(2017$ by authors, all rights reserved. Authors agree that this article remains permanently open access under the terms of the Creative Commons Attribution License 4.0 International License

\begin{abstract}
Need for a coherent and sound data base for policy making and decision taking on food and agriculture related issues was recognized while creating Food and Agriculture Organization of the United Nations (FAO). FAO, recognizing this need, developed food balance sheet in 1949 to bring together data on food supply and production for individual country and subsequently improved in stages. The last such improvement was released in 1996 in a publication entitled "System of Economic Accounts for Food and Agriculture" (SEAFA). SEAFA was designed to meet analytical needs for the formulation of plans and policies relating to food and agriculture by integrating various databases on production, consumption, capital formation relating to crop \& animal husbandry, forestry, fishery and food production. SEAFA provided support for analyzing efficiency of production of food and agricultural products and evaluating supply and use of food (in terms of level of nutrition intake). Main objectives of agricultural policies go much beyond this. Policy makers would very much like to look into ways and means to secure improvements in the production and distribution of food and agricultural products which could lead to improve the living condition of rural population. Some of these issues have been discussed at various international forums. However, to make a dynamic decision making it is necessary to integrate all issues in a single envelop. Basic architecture of SEAFA is based on production units viz. institutional units (like agricultural households), agricultural establishments and food \& agricultural products. This approach does not allow linking other issues like infrastructural needs, state of environment, etc. to the production system. In the present paper a revised extended system based on area as a unit for compiling the database has been proposed. The new system based on micro-macro linkage using bottom up approach for collection, compilation and analysis of food and agriculture data. The system propagates use of indicators. The approach has in-built advantage of optimum use of partial available data.
\end{abstract}

Keywords UNSNA, Integrated System, Food \& Agriculture

\section{Introduction}

Need for a coherent and sound data base for policy making and decision taking on food and agriculture related issues was recognized while creating Food and Agriculture Organization of the United Nations (FAO). FAO, recognizing this need, developed food balance sheet in 1949 to bring together data on food supply and agricultural production for individual country. This basic work was subsequently improved in stages and were made available in publications entitled "Agriculture sector accounts and tables: a handbook of definition and methods"(1956), "Handbook of Economic Accounts for Agriculture (EAA)" (1974) and a "System of Economic Accounts for Food and Agriculture" (SEAFA, 1996) [1]. While the 1956 publication contained standardized definitions and improving methods for collecting food and agriculture data, the EAA took into account recommendations made by UN Statistical Commission on national accounts to provide estimates of macro-economic aggregates for policy makers. The SEAFA took into account recommendations on accounts for institutional sectors and satellite accounting made by the UN Statistical Commission in SNA1993[2] the SEAFA was designed to meet analytical needs for the formulation of plans and policies relating to institutions dealing with production of food and agriculture products. In the System the databases on production, consumption, capital formation relating to crop \& animal husbandry, forestry, fishery and food production have been integrated at national level to provide following types of information:

a) production, productivity and income accruing from the activities of agriculture, forestry, fisheries and food production by type of institutions;

b) inputs and labor required for carrying out these activities;

c) consumption pattern, food habits and nutrient content of the food;

d) status of infrastructural development related to agricultural and food production activities and their financing requirements.

SEAFA, continuing from earlier efforts, provided an 
improved framework for analyzing issues relating to agricultural production and food consumption. However, as indicated in the Basic Text of the FAO, main objectives of agricultural policies ${ }^{1}$ would very much like to look into ways and means to secure improvements in the production and distribution of food and agricultural products which could lead to improving the condition of rural population and sustainable agriculture production plan. An analysis like this would cover issues relating to infrastructural developments, conservation of natural resources (land, soil and water), use of improved technologies, state of labor force engaged in agricultural activities (particularly unpaid family labor and women). These issues have been raised in various international forums and are becoming increasingly important in today's state of development. The present paper goes into details of needs of policy makers \& economic planners and suggests an information system for creating an integrated database that provides linkage between cause of retorted growth and effect of various policy actions.

\section{Recent Developments}

Agriculture is primary source of food. Forty-eight percent of total population (World Development Indicators) of the world lives in rural areas, of which ninety two percent belongs to the developing world. In general three fourth of rural population depends on agriculture (FAOSTAT www.fao.org). In many poor developing countries, primary activities such as agriculture are still backbone of the economy. Agriculture, being the primary economic activity connected with land and water, is also a major stakeholder for maintaining sustainable ecosystem. These facts have always remained centre of policy maker's interest and to improve the situation there has been a persistent demand for data.

Narain (2001) [3] recognized that two major new issues, namely, the need for a comprehensive approach for environmentally sound and sustainable economic development and the right to have access to safe and nutritious food, were raised at three important World Summits organized in early nineties. The first issue which was debated in the seventies and eighties was raised at the United Nations Conference on Environment and Development (Earth Summit, 1992) in the form of Agenda 21. This agenda highlighted the need for a comprehensive approach for environmentally sound and sustainable economic development. The second issue was recognized at the Copenhagen World Summit for Social Development (the Social Summit, 1996) and the World Food Summit (Food Summit, Rome 1996).

The Earth Summit was convened to address the urgent problems of environmental protection in relation to ongoing socio-economic development. Environmental statistics are multidisciplinary. They include a large set of physical

1 "Basic Texts" of the FAO, (www.fao.org) databases on climate (solar energy and light, water, wind, heat \& temperature), flora, fauna, etc. which are collected using various techniques and methods for a comparative analysis of their impact on the ecosystem and the social, demographic and economic conditions of the people. In order to achieve sustainable development, environmental protection shall constitute an integral part of the development process and cannot be considered in isolation from it.

At the World Food and Social Summits it was recognized that world population is growing and steps need to be taken urgently for eradicating hunger and malnutrition. The World Food Summit (WFS) declared that "Poverty is a major cause of food insecurity and sustainable progress in poverty eradication is critical to improve access to food. Conflict, terrorism, corruption and environmental degradation also contribute significantly to food insecurity. Increased food production, including staple food, must be undertaken. This should happen within the framework of sustainable management of natural resources, elimination of unsustainable patterns of consumption and production, particularly in industrialized countries, and early stabilization of the world population."

WFS recommended that a more complete and user-friendly sources of information at all levels shall be put together to foster greater efforts in this area. In order to do this, the Food Insecurity and Vulnerability Information and Mapping Systems (FIVIMS) concept was established by the FAO. The FIVIMS provides accurate and timely information relating to agriculture, health and ecosystem to enable the better assessment of the current situation of food insecure and vulnerable people. The immediate objectives of FIVIMS $^{2}$ at the national level are:

- to increase national and international attention to food security issues so that they receive higher priority in policy and program formulation;

- to provide reliable, quality, and timely national and sub-national food security related data;

- to enable multi-sectoral analyses through better integration of complementary information components;

- to promote better use of information for understandings of users' needs;

- to enable effective information dissemination for FIVIMS advocacy and implementation; and

- to improve users' access to information through networking and sharing.

Major thrust of the WFS as well as the Social Summit was on food for total population as a whole and did not make direct focus on agriculture. The follow-up to these Summits includes actions on economic and environmental issues at the national and international levels. These actions are related to people and institutions engaged in agricultural

2 For more details please refer to "Guidelines for National FIVIMS Background and principles" issued by Inter-agency Working Group on Food Insecurity and Vulnerability Information and Mapping Systems at www.fivims.net 
activity and the ecosystem. Two major programs were initiated at the end of nineteenth century and beginning of third millennium. UN, jointly with other international agencies, initiated two major programs. In these programs OECD remained at the centre. The two initiatives are "Partnership in Statistics for Development in the 21st Century (PARIS21)" and "Statistics, Knowledge and Policy: OECD World Forum on Key Indicators"

The PARIS21 was founded in November 1999 by the United Nations, the European Commission, the Organization for Economic Co-operation and Development, the International Monetary Fund, and the World Bank, in response to the UN Economic and Social Council resolution on the goals. PARIS21's vision is to reduce poverty and improve governance in developing countries by promoting the integration of statistics and reliable data in the decision-making process. The effort is dedicated to identify weaknesses in the data needed for policy formulation and to encourage ause of new data sources in developing countries for strengthening their National Statistical Systems.

"Statistics, Knowledge and Policy: OECD World Forum on Key Indicators" addressed key issues for the development of key indicators to show the development taking place in the economy. Effort is to make the process transparent and show accountability of public policies. This effort would enhance people's abilities to understand the characteristics and the evolution of their societies and would also support the role of the media in developing fact-based knowledge among citizens. All these issues require a special effort by modern societies to develop high quality statistics, share knowledge about the state and the development of the society.This System could be build either through traditional economic accounts based on GDP or by way of a composite indicators of wellbeing or by identifying a certain number of key indicators covering economic, social and environmental domains.

In the two initiatives listed above, although data on agricultural and rural areas are needed, no specific efforts were made to integrate these databases in the decision making process for bettering the conditions of rural populations. At the beginning of the third millennium, therefore, member countries have the primary responsibility for creating an economic and political environment that assures the sustainable maintenance of the global ecosystem and provides food security and better living conditions to their citizens. Agriculture, which is directly linked to natural resources, is at the centre of both of these issues. The Agricultural statistics system, therefore, needs to be geared up to meet this new demand. Going a step further from earlier efforts two significant steps have been taken in the last decade.

In 2003 the Inter-secretariat Working Group on Agriculture and Rural Indicator (IWG.AgRI) ${ }^{3}$ created a

3 Members of the Group are United Nations Economic Commission for Europe (UNECE), Organization for Economic Co-operation and Development (OECD) the Food and Agriculture Organization of the United Nations (FAO) and the Statistical Office of the European Community
Task Force on Rural Development Statistics and Agriculture Household Income (known as Wye Group) which drafted a proposal entitled "Handbook on Rural Households' Livelihood and Well-being: Statistics on Rural Development and Agriculture Household Income" in 2007.The proposals were accepted by the UN Statistical Commission. . Among many important conclusions drawn by the Group, some of the important one included - (1) For collecting important statistics a shift is required from a sectoral to a territorial approach to improve coordination and integrate various policy issues, (2) increasing use of partnerships between public, private and voluntary sectors for speedy implementation of policy measures, (3) area specifics characteristics need to be considered for preparing policies, and (4) giving importance to agriculture is essential in framing rural development policies. The Group has gone into many critical issues for framing concepts and definitions for collection and compilation of data. The basic approach of considering territory for collection and compilation of data by the Group is a step in right direction but at many places details included are predominately related to developed countries.

Another step in the same direction is Development of Global Strategy to improve Agricultural and Rural Statistics prepared jointly by the World Bank, FAO and UN Statistical Commission in 2011. "The Global Strategy to Improve Agricultural and Rural Statistics" provides the framework essential to meeting the current and emerging data requirements of policy makers and other data users. The conceptual framework presented in the Global Strategy brings together the economic, environmental and social dimensions of agriculture to monitor how the well-being of households is determined by the productivity of agriculture, the land they use and the environment they share. The work received strong support by donors and regional Commissions/ International bodies.

The Global Action Plan has recognized three pillars, viz. (a) establishing a minimum set of core data, (b) integrating agriculture into national statistical systems, and (c) importance of governance and statistical capacity building, for creating a sound foundation for decision makers. Comprehensive documents have been prepared on action plan to cover aspects like, country assessments, minimum set of core data, technical assistance plan, training plan, research plan, process to implement the Global Strategy., Indicative budget and timeline and monitoring, evaluation and reporting system have also been developed.. However, use of "area" as a basic unit for creation of the system was lost in this effort. Due to this limitation it becomes difficult to integrate environmental related data.

In the same period some efforts ${ }^{4}$ were also made to

(Eurostat).

4(a) Manual Environmental and Economic Accounts for Forestry: a tool for cross-sectoral Policy Analysis, FAO Forestry Department Working Paper (2004), (b) Integrated Environmental and Economic Accounts for Fishries, Studies in Methods, Handbook on National Accounting, United Nations \& FAO of the United Nations (2004), (c) Integrated Environmental and Economic Accounts for Water Resources, United Nations Statistics Division 
compile economic and environmental accounts for agriculture. These attempts have linked physical or monetary data on agri-environment related attributes to economic accounts. In actual practice it is not always possible isolate each and every expenditure/ physical assets at the sectoral level. Furthermore, scope of decision making on each issue does not fall under the preview of decision makers working on agriculture. This is more relevant for developing countries.

Yet another issue which has been discussed at length in last three decades and is equally important is the role of women in agriculture and rural development. The monitoring of gender related social processes generally concerns inequalities in the distribution of resources between women and men or unequal outcomes of equivalent efforts. This issue has been raised in the many international conferences such as World Conference on Education for all (WCEFA, Jomtien, Thailand 1990), UNECD - Earth Summit on environment (Rio de Janeiro, 1992), World Conference on human rights (Vienna, 1993), International Conference on population and development (Cairo, 1994) and Fourth World Conference on Women (Beijing, 1995). All these forums have discussed the issue from their perspective. Role of Women in agriculture and rural development are very wide and need careful examination to identify the linkages. They relate to increased demands on female labour; changing roles and responsibility of women in farm management, gender differences in access to resources, including land, water, credit and technologies; etc. These matters have been considered in detail by the FAO, IFAD, etc. However, it is essential to integrate this aspect also with the other issues.

It goes without saying that the hard work done in the last 10 to 12 years is of immense value, but one question remains - for whom? Who needs this system? Does a decision maker sitting in a remote developing country realize importance of such a system? And last but not the least, if external support is withdrawn can a country continue to maintain this system. Single reply to these questions is that developing countries need a system which could give action plan as per their local needs.

\section{Information System Needed by the Food and Agricultural Decision Makers}

The fundamental purpose of policy makersrelating to the food and agriculture has been set out in the Preamble of the FAO Constitution, which affirms the determination of

(2006), (d) Integrated Economic and Environmental Accounts for Agriculture - Etienne Verhaegen, Hilde Wustenberghs, Ludwig Lauwersand Erik Mathijs (Belgium -

http://www.unece.org/fileadmin/DAM/stats/documents/ces/ac.61/2004/wp. 48.s.e.pdf ), (e) Towards a System of Environmental Economic Accounting for Agriculture (SEEA-AGRI),

(ref:http://unstats.un.org/unsd/envaccounting/ceea/meetings/UNCEEA-6-2 7.pdf)
Members "to promote the common welfare by furthering separate and collective action on their part for the purpose of:

- raising levels of nutrition and standards of living of the peoples under their respective jurisdictions;

- securing improvements in the efficiency of the production and distribution of all food and agricultural products;

- bettering the condition of rural populations;

and thus contributing towards an expanding world economy and ensuring humanity's freedom from hunger (FAO - Basic Text)". Ways and means to achieve the objective have been discussed and debated in various forums keeping in view present perspective. A system that would meet these requirements efficiently needs data to prepare plans for efficient use of scarce resources to carry out development by taking into account the social, economic and environmental factors and, measure impacts of various policies on the economy. The three components of the Preamble would, therefore, include:

\section{A. Development}

- Input needs of the sector: ensure availability of agricultural inputs needed by the sector to guarantee plant nutrition and maintain soil fertility.

- Technological developments: encourage adoption of improved production technologies with respect to the utilization of labor, capital and natural resources (land and water).

- Resource monitoring: improved availability of credit.

- Human resource development: strengthen human resources (education, training and extension services) and institutional capacity.

- Social welfare: improve nutritional and health status and food quality.

- General economic growth: monitor needs for overall infrastructural development (roads, storage facilities, infrastructure for agro-industries, etc.) to induce rural development.

\section{B. Impacts of Various Policy Measures}

- Agricultural policy analysis: living standards of the population dependent on agriculture, terms of trade between agricultural and non-agricultural households, price behavior of agricultural products and subsidies, grants and taxes related to the agricultural sector, generation of employment opportunities, development of agro-industries.

- Linkages between agricultural activities and the ecosystem: contribute to the development by canvassing sound technologies based on research through extension services such as improved irrigation systems, croprotation, integrated pest management etc., to improve the general environment. 


\section{Allocation of Increasingly Scarce Natural Resources}

- Land and soil: initiate programs for land conservation and rehabilitation.

- Biological diversity: provide resources for conservation and improvement of plant and animal genetic resources.

These issues have been discussed at various forums and suggestions have been made for collection and compilation of data. The basic questions about these suggestions are - (a) Do each country requires same set of data? (b) Why these proposals are not acceptable as part of country's program in the long term? and (c) Why the program stops as soon as external support is withdrawn? Simple answer to all these questions is - all proposal/suggestions made are top-down and not bottoms-up. Data users at international level do feel that all these information are generally available in most of the countries. However, quality and reliability of these databases are not known. It is necessary to update and review the basic data and assumptions. This information is used either to review macro-economic situation in the country or for making international comparisons. These databases are not used to $t$ answer questions on policy options for inducing economic development. For a more acceptable proposal it is necessary to build a data base that could reveal cause and effect relation at grass root level. This calls for a bottom-up approach for compilation of aggregates.

Basic architecture of the integrated system would, therefore, start from bottom most (local administrative) units that are linked to national level macro aggregates/ accounts. For formulation and successful implementation of economic plans and polices relating to agricultural production and distribution, information/data are needed on - (a) economics of agricultural production units, (b) pattern of land use, (c) economic activity of the people living in the area, (d) status of infrastructure in the area, and (e) status of agricultural resources (land, irrigation system, etc.,) in one frame. For critical evaluation of the local unit, therefore, geo-referenced database on agricultural resources are required for direct linking policies and program to the place of action. In the present paper a new system has been proposed which is based on area as a unit for compiling the database.

The system is created using recommendations of UN SNA 1993(paragraphs 19.40 to 19.61) as a three tier set with accounts and supporting statements. While the socio-economic data are based on common concepts and definitions for all local units, data on natural resources (climate, soil and water) differs from one unit to other depending on the agro-climatic zone to which the unit belongs to. This system enables statistician to economize (as data for only relevant characteristics need be collected) on resources needed for collection of data on natural resources that may also sometime need special high-tech scientific methodology and instruments. This system provides basis for "cause and effect analysis" suitable for the area. An over view of the system is given in Annex B. The system assumes existence of three tier government having a regional and local level. This, however, depends on size of country (as some small countries do not have regional level). Integrated system is described below:

1. For creating internationally comparable consistent database the system is based on basic concepts and framework given by UN SNA ${ }^{5}$. Concepts and definitions given by the UNSNA have been supplemented with the concepts given in the SEEA on classifications of natural resources (land and soil degradation, agro-climatic zone concepts, sustainable yield, etc. that are used by agriculture scientists).

2. The system uses concepts of regional accounts and satellite analysis to inter-link various databases. Keeping in view complexity of creating integrated accounts that includes environmental aspects and status of infrastructural support, satellite analysis has been included which link economic statistics to the physical data-base. The approach has added advantage of providing direct information on issues requiring attention (such as causes of low yield, factors effecting low farm gate prices as compared to high wholesale prices). Analysis does not go to indirect measures based on prices, taxes, subsidies which generally considered by the Ministry of Finance etc. keeping in view numerous other activities that may not be relevant to agriculture.

3. This System is based on collection compilation and presentation of food and agriculture data on production, consumption, infrastructure for units of land area which are predominantly agriculture ${ }^{6}$ in nature. This, concept is slightly different from the concept of rural area. Generally rural areas, as defined in population census, etc., are determined by number of people living in the "administrative" land area. However, the proposed unit can be treated as a sub-set of the rural area, if need be.

4. The system is based on integration of geo-referenced data collected in socio-economic surveys \& censuses, remote sensing data and administrative data (See Kabat, at. al. 2000 for further details)[4]. The system recommends use of multiple frames survey techniques to collect socio-economicas well as remote sensing data. For making the system cost effective use of small area (sampling) techniques have been suggested.

5. The system propagates use of indicators originating from economic and environmental accounts as well as

5Use of SNA format enhances consistency and supports geo-referenced analysis of various databases in one framework. In the proposed framework, the total structure is based on Supply and Use Table as recommended by the UNSNA (UNSNA 2008, paragraph 29.21) and production units are grouped to show elements of the production account and generation of income account. As recommended by SEAFA, these accounts are compiled for institutional units, establishments (especially agricultural households) and parcels used for producing agricultural products to study their cost of production and income generation aspects. To support this analysis and analyzing income accrual and use of capital, some supplementary accounts have been proposed in the SEAFA.

6 The term "agriculture" is used in a broad sense to cover agriculture, forestry, fisheries, land and water, agro-industries, environment, manufacturing of agricultural inputs and machineries, regional and river development, and rural development. 
suggested by other studies related to growth models, market intelligence, etc. The set of indicators includes general purpose indicators on growth, share, etc.; agri-environmental issues; nutritional status; productivity; levels of living of agri-households; gender main-streaming; terms of trade; infrastructural development at national, regional and local level required for decision making. The system would be having micro-meso-macro level linkage for deciding inter-se priorities in allocation of resources for local level development. The approach has in-built advantage of optimum use of partial data, i.e., even if sufficient/reliable data on all aspects of the economy are not available to compile a full sequence of accounts partial available data could be used to compile indicators.

6. To bring out role of unpaid family workers and women in agriculture (which is a common issue in developing countries) use of "Time use surveys" has been suggested.

7. At national level the system is initiated with Supply and Use Table that has been linked to Accounts for Institutional (Corporate, NPI, households) Units and Agricultural Establishments. Concept of, Satellite Accounts has been used for compiling Food Balances. In addition to this, data on work force, land use ${ }^{7}$ and current status of infrastructural development supplement the System as recommended by the SEAFA. (see Annex B)
8. At the second level (regional level) data are compiled on agricultural institutions and establishments. Types of institutional units to be considered in the context of regional accounts are given in SNA 2008 (paragraph 18.47)

9. Primary data base are built at the third (local) level which is the basic unit for decision making. Data on natural resources are collected based on agro-climatic zone (FAO 2003 ${ }^{8}$ )[5] in which the unit is located.

Such an information system that could provide support to decision makers in the formulation of policies requires large amount of statistical data relating to (a) economic forces (e.g. production, input, prices, wages, food consumption, macro-economic aggregates, aids and assistance) (b) human resources (population, labour force) (c) natural resources (soil, water, climate). One of the common constraints for creation of such a system is that the various data components used in the system need lot of resources, both in terms of funds as well as technical manpower and equipments. Apart from that collection and processing of data is time consuming process. It is therefore suggested that to give a start, conceptual framework of the system may be prepared giving detailed concepts and definitions and the existing data that are available may be re-tabulated as per the framework. For filling the data gaps a few local areas may be selected and work on collection of data may be initiated as a pilot project.
7 Present classification of land use is not suitable for proper land use planning. A more dynamic classification is required for the present purpose. For further details see Narain (2010) [6]/Annex D.
8 It has been recognized that while some countries are facing problems in selecting appropriate indicators to meet their requirements, others are finding it difficult to define the type of data needed for compiling indicators. This Handbook addresses these issues. Just to illustrate procedure for selecting indicators it has considered four agro-climatic regions (Fragile ecosystem of mountain areas, dry region, high rain fall fertile region and arid to semi-arid region with highly developed irrigation system). The Handbook also provide support for analyzing data by indicating the relevant level at which an indicator could be used 


\section{Annex A - Overview of the Integrated System}

\begin{tabular}{|c|c|c|}
\hline \multicolumn{3}{|c|}{ Database } \\
\hline Census \& Surveys & Remote Sensing \& Other Scientific data & Concepts and Definition \\
\hline \multicolumn{2}{|c|}{ Data Collection Tools } \\
\hline UNSNA, SEEA \& Time Use Surveys supplemented with land use classification \& other sources related to natural resources \\
\hline Multiple frame survey, Small area estimation techniques \\
\hline
\end{tabular}

\section{At National Level}

\section{Satellite Accounts For Food Balances}

Accounts For Institutional Units

Accounts For Agricultural Establishments
SUPPLY

AND

USE

TABLE
Aggregate Picture Of Infrastructure

Aggregate Picture Of Agricultural Resources

\section{At Regional Level}

Accounts For Regionally Owned Corporate Units Aggregate Picture Of Infrastructure
Accounts For Agricultural Households

Aggregate Picture Of Agricultural Resources

\section{At Local Level}

Production \& Generation of income account for agricultural households and parcel of agricultural land
Database on agriculture production, land quality, resources and infrastructure status 


\section{Annex B - Integrated System for Collection and Analysis of Food and Agricultural Data}

\begin{tabular}{|c|c|c|}
\hline \multicolumn{3}{|c|}{ A. Focal Unit of Analysis } \\
\hline Agricultural Product & Agricultural Holding & Agricultural Institution \\
\hline \multicolumn{3}{|c|}{ B. Coverage } \\
\hline $\begin{array}{l}\text { Principal agricultural products and their } \\
\text { by-products resulting from economic } \\
\text { activities under International Standard } \\
\text { Industrial Classification Group } 01\end{array}$ & $\begin{array}{l}\text { Principal agricultural products and } \\
\text { outputs of secondary activities } \\
\text { performed at the holding whether } \\
\text { agricultural or non-agricultural }\end{array}$ & $\begin{array}{l}\text { Total economic activities of all } \\
\text { agricultural institutions - household, } \\
\text { corporate or government - whose major } \\
\text { share of income originates from } \\
\text { agricultural activities }\end{array}$ \\
\hline \multicolumn{3}{|c|}{ C. Data } \\
\hline $\begin{array}{l}\text { Area, production, trade (export and } \\
\text { import), utilization (final and } \\
\text { intermediate), prices, nutrient content }\end{array}$ & $\begin{array}{l}\text { Area, outputs, inputs, capital and labor } \\
\text { used in production, seed variety, details } \\
\text { of soil management and farming } \\
\text { practices }\end{array}$ & $\begin{array}{l}\text { Income, expenditures, outputs, inputs, } \\
\text { capital and labor used, consumption, } \\
\text { assets and liabilities, socio-economic and } \\
\text { demographic data, taxes and subsidies }\end{array}$ \\
\hline \multicolumn{3}{|c|}{ D. Uses } \\
\hline $\begin{array}{l}\text { Total agricultural production } \\
\text { Distribution of production by } \\
\text { commodity, region, type of institution, } \\
\text { agro-climatic zone } \\
\text { Index number of production, inputs and } \\
\text { prices } \\
\text { Input-output projections } \\
\text { Studies of nutritional intake of the } \\
\text { population } \\
\text { Economic indicators }\end{array}$ & $\begin{array}{l}\text { Productivity studies, production } \\
\text { functions, capital-output ratios, } \\
\text { input-output coefficients } \\
\text { Economic and environmental indicators } \\
\text { Impacts of agricultural adjustments and } \\
\text { government policies } \\
\text { ABC analysis of research and extension } \\
\text { priorities and personnel development } \\
\text { plans }\end{array}$ & $\begin{array}{l}\text { Studies of living standards of population } \\
\text { dependent on agriculture } \\
\text { Studies on poverty and food security } \\
\text { Framing of government policies relating } \\
\text { to taxation, prices and subsidies } \\
\text { Studies of terms of trade } \\
\text { Formulation of macro-level models }\end{array}$ \\
\hline \multicolumn{3}{|c|}{ E. Tools } \\
\hline $\begin{array}{l}\qquad \text { SEAFA: } \\
\text { Goods and services account } \\
\text { Satellite accounts for food balances and } \\
\text { supporting statements } \\
\text { Supply and utilization account } \\
\text { Food balance sheet } \\
\text { Input-output table }\end{array}$ & $\begin{array}{l}\text { SEAFA: } \\
\text { Production, generation of income, capital } \\
\text { accounts and supporting statements } \\
\text { Input-output table }\end{array}$ & $\begin{array}{l}\text { SEAFA: } \\
\text { Production, generation and distribution } \\
\text { of income, capital accounts and } \\
\text { supporting statements } \\
\text { Multi-subject (integrated) household } \\
\text { surveys }\end{array}$ \\
\hline
\end{tabular}

\section{Annex C - Comprehensive Land Use Classification - Extract}

1. Total Area (Total area of the country including area under water, etc.)

1.1 Area not in use (excluding areas that were in use once, but are no longer in use due to degradation, etc.)

\subsubsection{Land area}

- Land under glaciers and perpetual snow and other land (not elsewhere classified)

- Land under vegetation (closed forest areas)

- Land under desert

\subsubsection{Land under water (Area under tidal water)}

\subsection{Area in use for undertaking economic activities}

\subsubsection{Land area}

- Land under single use (details as per concepts given by ISIC)
- Land under multiple use ${ }^{9}$

- Net land area under use

- Gross land area under use (Details as per concepts given by ISIC)

- Intensity of use $[(\mathrm{b}) /(\mathrm{a})]$

- Land not in use due to degradation

- Other land area (not elsewhere classified)

\subsubsection{Land under water (Area under water)}

- Land under water in single use (details as per concepts given by ISIC)

- Land under water in multiple use

- Net land area under water in economic use

- Gross land area under water in economic use (Details as per concepts given by ISIC)

- Intensity of use $[(b) /(a)]$

- Land under water not in use due to degradation 
- Other land under water (not elsewhere classified)

In building these associations, one can easily use principles laid down in ISIC for classifying activities into principal, secondary and ancillary activities and their association to the owner of the unit. To meet the needs of multiple users, one may consider taking ISIC classes and superimposing other details at the second level. For example, in the case of crop husbandry, detailed data may also be required on area under different crops or characteristics of soil for considering specific issues ${ }^{10}$ like soil degradation/erosion due to wind, water and sedimentation, water logging, salinization, shifting cultivations.

The classification based on such a framework would be:

- Fully compatible with ISIC. As many users are familiar with ISIC, the system would be simple to understand and flexible to incorporate needs of different stake-holders.

- Fully compatible with FAO's land cover classification and could be used for projecting changes in land cover vis-à-vis land use.

- Independent of legend required by different stake-holders. It would be possible to aggregate data on different scales and mapping units.

- Able to facilitate analysis of impact of different economic activities as well as impact of nature's vagaries on areas under land and water.

- It would be feasible to super-impose further details according to user's need to support better land use planning.

This framework would also provide a correspondence between land and labor and capital employed, as well as with the goods \& services produced. However, in order to attempt such a classification, it would be necessary to undertake further inter-disciplinary work to define appropriate classes and guidelines for deciding boundary line issues.

10 Over the last two decades the Land and Water Development Division (AGL) FAO has been at the forefront of the development and application of computer-based systems to analyze data and generate information to support decisions on various land and water issues. Separate soil and land and water systems (such as: AEZ - Agro-Ecological Zoning System, SDBm Multi-Lingual Soil Database, SOTER - Soil And Terrain Database, DSMW Digitized Soil Map Of The World, FAO/ITC Land Use Database, ECOCROP 1 - Crop Environmental Requirements Database, ECOCROP 2 Crop Environmental Response Database, WOCAT - World Overview of Conservation Approaches and Technologies, DTIPNS - Database Tool for Integrated Plant Nutrition Systems, MCDA - Multi-Criteria Decision Analysis techniques, CLIMWAT - Climatic Database, CROPWAT - a computer program for irrigation planning and management, SIMIS - Scheme Irrigation Management Information System) have been developed. The soil and land systems focus on methodologies and tools for the assessment of land resources potentials at global, regional and national and sub-national levels. The water systems concern irrigation water use and management at field level and water resources assessment at regional and national levels. For summary please refer to "Information technology and decision-support systems in AGL - Background Paper" prepared by J. Antonie, Soil Resources, Management and Conservation Service, Land and Water Development Division, FAO, Rome, Italy In: Proceedings; World Soil Resources Reports (FAO), no. 89; Sub-regional Workshop on Land Resources Information Systems for Food Security in SADC Countries, Harare (Zimbabwe), 3-5 Nov 1999, p. 9-14.

\section{REFERENCES}

[1] FAO (1996): .A System of Economic Accounts for Food and Agriculture (SEAFA) FAO Statistical Development Series number 8 (1996).

[2] United Nations (1993, 2008): System of National Accounts

[3] L. Kabat, L. Naiken and P. Narain (2000): Data integration and its role in the development of better agriculture and food information systems by paper prepared for Invited Paper Session 15 - Integrating Agriculture and Food Statistics: National and International Perspectives, of the International Conference on Establishment Surveys - II organized jointly by USDA, Statistics Canada, ASA at Buffalo, NY, USA - June 2000.

[4] Narain, P (2001): The Response of Agricultural Statistical Systems to the New Demands - Invited paper prepared for the International Conference on Agricultural and Environmental Statistical Applications (CAESAR), 5 - 7 June 2001, Rome, Italy.

[5] FAO (2003): Collection of data and compilation of agri-environmental indicators - a step by step guide, (mimeograph)

[6] Narain, P (2010):LAND USE CLASSIFICATION: CONCEPTS \& METHODS-Towards an improved information basis, Paper submitted to Session 4.2 Environment statistics including land and water use Core indicators, cross-sectoral indicators, etc., ICAS V. 